TUBERCULOSIS AND THE MILK·SUPPLY. To the Editor of THE LANCET.

SrR,-A conference was held at the Town Hall, Manchester, on Feb. 28th, of delegates representing the public health committees of the cities of Liverpool, Manchester, Birmingham, Leeds, and Sheffield in regard to the danger to man of milk containing the living infection of tuberculosis. Each of the above cities has had by reason of local Acts of Parliament considerable experience in the examination of samples of dairy milks for this infection. The result of this experience may be briefly stated by saying "that the milk in about 10 per cent. of the churns sent into these towns contains the living infeotion of tuberoulosis." From experience elsewhere it is almost certain that this high proportion is exceeded in many districts.

The report of the Royal Commission on Tuberculosis issued in January, 1907, states that "there can be no doubt that in a certain number of cases the tuberculosis occurring in the human subject, especially in children, is the direct result of the introduction into the human body of the bacillus of bovine tuberculosis; and there can also be no doubt that in the majority at least of these cases the bacillus is introduced through cows' milk. Cows' milk containing bovine tubercle bacilli is clearly a canse of tuberculosis and of fatal tuberculosis in man."

With this important statement, and the knowledge that in their own towns the amount of infected milk was large, the conference decided to approach the Government with a view to getting effective steps taken to eradicate bovine tuberculosis. The conference felt much strengthened in urging adequate preventive measures by the knowledge that any steps which will effectively deal with the tubercle. infected milk will at the same time benefit all consumers of milk in the direction of insuring a cleaner supply. And again, they feel that the direct benefit to farmers and butchers in preventing loss due either to the reduced value of the stock or to the seizure of tubercular meat intended for human food will be an important one. The conference passed the following resolution :-

That having regard to the experience of the five towns whose delegates have conferred on this subject, and also to the return recently made to the House of Commons at the request of Dr. Rutherford, a representation be made to the Presidents of the Local Government Board and the Board of Agriculture and Fisheries with view to inducing these Boards to take effective steps to enforce uniformly throughout the country proper and suitable inspection of dairies and cowsheds, and for regulating the construction of such dairies and cowsheds so as to insure cleanliness and suitable hygienic conditions; and further, that the Government be respectfully asked to include in their prospective legislation dealing with milk, clauses calculated to bring about the eradication of tuberculosis from bovines within a measurable period of years.

It is intended to present this resolution to both the Local Government Board and the Board of Agriculture. I am, Sir, yours faithfully,

THOMAS FLETCHER

Chairman of the Conference and Chairman of the Health Committee of the Corporation of Birmingham.

The Council House, Birmingham, March 2lst, 1908.

\section{CALMETTE'S TUBERCULIN TEST IN 210 ASYLUM PATIENTS.}

To the Editor of THE LANCET.

SIR,-I have recently applied the Calmette test to 210

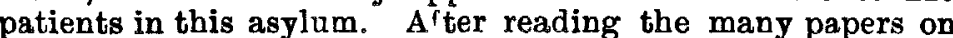
the subject I took the reliability of the test for granted and undertook its application with a view to ascertaining the proportion of tubercular cases here, influenced as I was by the proposed building of a verandah for such patients and the question of the necessary amount of accommodation to be provided. In performing the test I left out every patient where struggles or excitement was likely to interfere with the proper application of the tuberculin to the eye. I selected only those whose eyes were healthy. The 210 patients constituted 80 per cent. of the total paupers resident. At the time there was only one case of active phthisis. This girl, tested with a solution of 1 in 150 , gave the reaction in three hours. There were also four cases where the patients had during the past two years suffered from active pulmonary tuberculosis, but all were in a quiescent state and in good condition after prolouged open. air treatment. All four reacted to a 1 in 150 soluticn. Of the others 91 patients gave a positive reaction. Many of these were undoubtedly of poor nutrition but none of them as yet have furnished any other proofs of tubercle.

One hundred cases were tested with the 1 . in 150 solution, the remaining 110 with solutions varying in strength from 1 in 300 to 1 in 700 . Taken in batches of 25 for each particular solution it was found that there was a slightly reduced proportion of positive reactions as the solution was weakened. In the batch tested with 1 in 700 there were six positive reactions ; two of these in very healthy persons were the most violent reactions of all the cases. If the test be reliable it cannot anywhere be of such service as in an asylum where the symptoms of tubercle like those of other diseases are often more obscure than usual and where early separation of the affected cases is so desirable. This asylum has had for years the reputation of being singularly free from tubercle, though in the past year the death-rate from phthisis has gone up, but a proportion of nearly 50 per cent. of positive reactions to the Calmette test suggests either a serious condition of affairs here or a want of reliability in the test. It would be rash in view of other experiments performed by specialists to accept the latter theory and so it seems to me that it is not verandahs or sanatoria for consumptive patients alone that we so much need as a general extension of the system of open-air treatment of all the insane.

I am, Sir, yours faithfully,

James P. Sturrock, M.A. St. And., M.D. Edin.

Midlothian and Peebles Asylum.

\section{A DIAGNOSTIC SIGN OF INFLUENZA.}

To the Editor of THE LANCET.

SIR,-Since the reappearance of influenza in $1889 \mathrm{I}$ have attended many thousands of cases and for several years have noticed that in every case there is present a swelling or cedema of the urula. This swelling gives the uvula a pale, waxy, cdematous appearance. It is found at the commencement of the attack and usually lasts for several days. It is often present before there is any rise of temperature and remains after the temperature has fallen to normal. It is therefore useful in diagnosing very early cases and also those seen after the acute symptoms have passed off. I believe this cedema of the uvala is a certain sign of influenza. The present epidemic will give many medical men an opportunity of observing this sign.

I am, Sir, yours faithfully,

Bedford, March 28th, 1908. W. GIFFORd NASH.

\section{THE PRESENT PROSPECTS OF THE MEDICAL PROFESSION. \\ To the Editor of THE LANCET.}

SIR, - I have to sincerely thank you for the patient and impartial hearing you have given me on the above matter and, if $I$ am not mistaken, time will show that there are a great many besides myself-general practitioners, "specialists," and public-who will also bave reason to be grateful to you. If Dr. Saundby will refer to my letter of March 14th ult. he will see that I specifically mentioned that " the patient or the patient's friends must needs agree" to my proposal : that one-third of an upset fee for surgical (or special medical) treatment and after-attendance with assistance at operation be paid "on the nail " to the family practitioner and two-thirds to the so.called "specialist," the fees of either practitioner ranking equally as when and how paid or payable in due proportion. Dr. Saundby has no doubt misunderstood me and as a consequence bas misrepresented me, so that his "slight modification" was quite unnecessary.

The main point is, that my proposal is, according to $\mathrm{Dr}$. Saundby, late President of the British Medical Association, chairman of its ethical committee, member of the General Medical (Oouncil, and an acknowledged author of a valuable work on ethics, "a perfeotly honest and fair transaction." That is my point fully conceded and the rest does not now matter.

What is to be expected from this important reform in medico-chirurgical tariff? (a) It will be a powerful lever in stopping hospital abuse; $(b)$ it will meet the pockets of patients whose resources are slender, but who desire to pay for what they get in proportion; $(c)$ it places the interests of the general practitioner and "specialist" on an equal 